\title{
Inverse relationship between cod recruitment in the North Sea and young fish in the continuous plankton recorder survey*
}

\author{
JOHN A. LINDLEY ${ }^{1}$, PHILIP C. REID ${ }^{1}$ and KEITH M. BRANDER ${ }^{2}$ \\ ${ }^{1}$ Sir Alister Hardy Foundation for Ocean Science, The Laboratory, Citadel Hill, Plymouth, PL1 2PB, UK. \\ E-mail jal@pml.ac.uk \\ ${ }^{2}$ International Council for the Exploration of the Sea, Palaegade 2-4, 1261 Copenhagen, Denmark.
}

\begin{abstract}
SUMMARY: There is a significant $(\mathrm{p}<0.01)$ negative correlation between cod recruitment (age 1 year) and the numbers of young fish taken in the Continuous Plankton Recorder (CPR) Survey in the North Sea. This correlation is analysed with reference to hydrographic, climatic and biological variables in order to determine whether it results from opposite responses to physical forcing, trophic relationships or a combination of these. The results of correlation analyses are consistent with cod recruitment being determined mainly during the planktonic phase of development in the preceding year. Multiple regressions indicate that a combination of the North Atlantic Oscillation index in the preceding year and the abundance of CPR young fish is the pair of variables that provide the best fit to the data. The abundance of CPR young fish is best predicted by the Gulf Stream North Wall Index and the abundance of phytoplankton in the spring of the previous year. Opposite responses to climatic forcing and the regional environmental consequences are identified as of primary importance but interactions, possibly both predation and competition, occur between the planktonic stages of cod and both the planktonic stages of fish and the stocks from which they were derived.
\end{abstract}

Key words: cod, recruitment, plankton, long-term changes.

\section{INTRODUCTION}

Cod, Gadus morhua, in the North Sea are near to the southern limits of the distribution of the species in the eastern Atlantic area. Historically, strong year classes have been associated with lower than average temperatures, exceptions occurring when spawning stocks were low. High temperatures and low recruitment have been observed since 1988 except in 1996, which was unusually cold for this period (O’ Brien et al., 2000). Rodionov (1995) proposed that fluctuations in cod recruitment across the Atlantic were coherent due to atmospheric telecon-

*Received August 11, 2000. Accepted January 15, 2002. nections, implicating basin wide climatic processes rather than local physical or biological variables.

Knowledge of factors influencing recruitment is necessary to predict future fish stocks from data on existing stocks. Horwood et al. (2000) show that the main source of regulation of fish stocks is in the planktonic phase and that this is where research is needed. Svendsen et al. (1995) found that $>70 \%$ of variability in recruitment in several fish stocks in the North Sea can be accounted for by climate or weather before or during the larval stages.

A variety of mechanisms have been proposed to explain variations in egg production and larval and juvenile survival and hence recruitment to the spawning and commercially exploited stock. Cushing 
(1969) proposed the "match-mismatch" hypothesis, suggesting that timing of larval production was matched with the seasonal production of plankton as potential food. Calanus finmarchicus, as the dominant filter feeding copepod in the spring in the central and northern North Sea, was thought to be of particular importance, but Brander (1992) showed that there were trends in C. finmarchicus which did not correlate with cod recruitment. However, Rothschild (1998) showed that the smaller copepods identified collectively in the CPR survey as Para-Pseudocalanus should also be taken into account. He concluded that a large year class of either Calanus or Para-Pseudocalanus was required for a large year class of cod, but did not guarantee it. Brander and Hurley (1991) and Brander (1994) examined variations in the timing of cod spawning and concluded that the match-mismatch hypothesis could not be rejected although the evidence was weak.

In analyses of relationships between fisheries statistics and the results of the Continuous Plankton Recorder (CPR) survey (Reid et al., 2000), a significant negative correlation was found between cod recruitment and the abundance of larval and juvenile fish in the CPR survey. The most abundant young fish in CPR samples from the North Sea are Clupeidae and Ammodytidae (Bainbridge and Cooper, 1971; Coombs, 1980). In the southern North Sea the clupeids occur mainly between June and August and are mostly sprat, Sprattus sprattus, but herring, $\mathrm{Clu}$ pea harengus, are dominant further north and mostly occur between July and September (Bainbridge et al., 1974; Coombs, 1980). According to Hart (1974) the Ammodytidae taken in CPR samples in the North Sea are mainly Ammodytes marinus. The larvae are most abundant between February and May in coastal waters and the Southern Bight, with few occurring in the central and eastern areas of the northern North Sea (Coombs, 1980). Cod larvae are rare in CPR samples but post-larvae are found in the North Sea from February to August with a peak in April (Coombs, 1980). The negative correlation could be a result of contrasting responses to climatic influences and their effects on the physical environment or an indication of the effects of predation or competition for food resources.

By using the long-term data of the Continuous Plankton Recorder (CPR) survey in conjunction with the data from the ICES Advisory Committee on Fishery Management we seek to identify some of the environmental factors influencing recruitment of cod and the numbers of fish larvae and early post- larvae in the CPR survey. The objective is to consider whether the data support inverse responses to climatic variation or trophic interaction as the most likely cause of the inverse correlation between cod recruitment and the abundance of CPR young fish. This provides a contribution to determining which variables should be taken into account to predict cod recruitment and thus future stock size.

\section{METHODS}

Cod recruitment data and other fisheries statistics were taken from the GLOBEC database, available on the Internet at http://www.ices.dk/globec/, updated and amended from Anon. (1999). These data are not confined to the North Sea (ICES area IV) in all cases as the assessed stocks species may extend to adjacent areas such as the Skagerrak or Eastern English Channel. The fish data used here include spawning biomass of plaice, sole, saithe, cod, haddock, whiting, Norway pout, sandeel, herring and mackerel as well as cod recruitment.

The CPR survey has been described by Warner and Hays (1994). The CPRs are towed by ships of opportunity on standard routes at a constant depth of about $7 \mathrm{~m}$ (Hays and Warner, 1993). Phytoplankton colour, a coarse visual assessment of chlorophyll (Hays and Lindley, 1994), is assessed as the band of filtering gauze on which the plankton is caught is cut into individual samples (Rae, 1952; Robinson and Hiby, 1978). These samples, each representing the plankton retained from approximately $3 \mathrm{~m}^{3}$ of water sampled over 10 nautical miles (approximately $18 \mathrm{~km}$ ) of tow, are analysed including counting the total numbers of fish. The fish are mostly larvae and young juveniles and are described subsequently in the paper as CPR young fish. Sampling started in the North Sea in 1931 and a continuous time series is available from 1948 with zooplankton analyses using constant methods (Rae, 1952; Colebrook, 1960). Young fish have been identified to species as a specialist task, not part of the routine analysis of CPR samples, from 1932 to 1939 and 1946 to 1978.

The interannual variations in cod recruitment (age 1 year) and abundance of CPR young fish were analysed in relation to physical parameters, climatic indices, fish biomass and results from the CPR survey. The CPR data used were annual mean phytoplankton colour, annual zooplankton biomass (calculated as described by Reid et al., 2000), the timing 
of zooplankton (calculated according to Colebrook and Robinson, 1965) and each of these values calculated for January to July only. The timing of phytoplankton colour between January and July gives an estimate of the timing of the spring bloom (Colebrook and Robinson, 1965). The physical data used in the analyses -seasonal and annual mean sea surface temperatures and annual mean salinity of the North Sea- were provided by ICES. Temperature difference, a parameter to assess stratification by measuring the rate of increase of temperature during early summer (Craig, 1960), was calculated. This parameter is highly correlated with the timing of the spring bloom of phytoplankton (Robinson, 1970). Two climatic indices were examined, the Gulf Stream North Wall Index (GSI) described by Taylor (1995), data for which are available from http://www.pml.ac.uk/gulfstream/, and the North Atlantic Oscillation Index as defined by Hurrell (1995), with data from http://www.cgd.ucar.edu/ cas/climind/nao winter.html (now available on http://www.cgd.ucar.edu/ jhurrell/nao.html).

In many of the data sets examined here there is autocorrelation due to strong persistence from one year to the next, systematic patterns of environmental change or a combination of these. The correlations between each of the data sets used in analyses and the same data lagged by 1 to 10 years were calculated. Where significant autocorrelation was detected, the data were analysed to determine whether there were linear trends.

Product moment correlation coefficients were calculated between pairs of variables. Significance of values was derived for each value from statistical tables and then assessed using the Bonferroni correction for multiple comparisons (Miller, 1981). The correction, which was applied separately to each of the sets of correlation analysis described here, consists of adjusting the alpha values according to the number of comparisons. The correction was applied without taking into account the interdependence of some of the variables and consequently the real level of significance will fall between the unadjusted and adjusted values. Where significant correlations were found between variables of which at least one demonstrated a significant long-term linear trend, the correlation coefficients were recalculated, using the deviations from the trend line in place of the original data, to identify residual correlation.

Multiple regression equations were fitted to the data for cod recruitment and CPR young fish using the variables selected on the basis of the previous analyses. Each combination of two or more variables was used and the best fits to the actual data were identified.

\section{RESULTS}

The results of the analysis of autocorrelations are shown in Table 1. There was no autocorrelation evident in the cod recruitment but the CPR young fish showed significant correlations for lags of 1 to 6 years. The phytoplankton colour index was strongly autocorrelated but the zooplankton was not. Spawning stock biomass figures were all strongly autocorrelated, with the exception of the sandeels, and in the case of Norway pout the autocorrelation was only significant for the data set correlated with itself lagged by 1 year.

Correlations between CPR young fish data from the North Sea and spawning stock biomasses of commercial fish are listed in Table 2. There are significant positive correlations with herring and sole but negative correlations with most gadoids. It should be noted that although there is a weak positive correlation with mackerel using the data up to 1984, if arbitrary values of 0 tonnes or 10000 tonnes are used for missing values in later years for the depleted North Sea spawning stock then the correlation becomes significantly negative.

Year to year variations in cod recruitment in the North Sea and adjacent areas and the numbers of young fish in the CPR are shown in Figure 1a and b and the plot of these two variables against each other is shown in Figure 1c. The linear long term trends are in opposite directions and the five-year running means show an increase in cod recruitment and a decline in CPR young fish through the 1970s and a reversal of these trends through the 1980s. The correlations between cod recruitment and CPR young fish and between each of these and the other in the previous two years before and after removal of the long-term trend from the CPR young fish data are shown in Table 3. Cod recruitment is uncorrelated with CPR fish from the previous year. In contrast, the negative correlation between cod recruitment and CPR young fish two years previously is as strong as that with CPR young fish in the same year and remained significant after removal of the trend. There is a significant negative correlation between CPR young fish and cod recruitment one year previously, but it is weaker than for the current year and not significant after removal of the trend and adjust- 
TABLE 1. - Autocorrelation in datasets included in the analyses in this paper. Cod Rec $=$ cod recruitent, CPR fish $=$ young fish in the CPR survey, $\mathrm{P}=$ phytoplankton colour index (annual), $\mathrm{P}_{\mathrm{j}}=$ phytoplankton colour index (January to July), $\mathrm{Z}$ =zooplankton biomass (annual), $\mathrm{Z}$ = zooplankton biomass (January to July), $\mathrm{T}_{\mathrm{P}}=$ timing of phytoplankton biomass (annual), $\mathrm{T}_{\mathrm{Pj}}=$ timing of phytoplankton biomass (January to July), $\mathrm{T}_{\mathrm{z}}=$ timing of zooplankton biomass (annual), $\mathrm{T}_{\mathrm{zj}}=$ timing of zooplankton biomass (January to July), $\mathrm{N}$. Pout $=\mathrm{Norway}$ pout, $\mathrm{T}\left({ }^{\circ} \mathrm{C}\right.$ ) $=$ Temperature (annual), Sp T $\left({ }^{\circ} \mathrm{C}\right)=$ Spring temperature, $\mathrm{Su} \mathrm{T}\left({ }^{\circ} \mathrm{C}\right)=$ Summer Temperature, Au $\mathrm{T}\left({ }^{\circ} \mathrm{C}\right)=$ autumn temperature, Wi $\mathrm{T}\left({ }^{\circ} \mathrm{C}\right)=$ winter temperature, $\mathrm{TD}=$ Temperature difference, GSI $=$ Gulf Stream North Wall Index, NAO = North Atlantic Anomaly. * p 0.05>0.01, $* * \mathrm{p} 0.01>0.001, * * * \mathrm{p}<0.001$.

\begin{tabular}{|c|c|c|c|c|c|c|c|c|c|c|}
\hline Lag & Cod Rec & CPR fish & $\mathrm{P}$ & $P_{j}$ & $\mathrm{~T}_{\mathrm{p}}$ & $\mathrm{T}_{\mathrm{pj}}$ & $\mathrm{Z}$ & $\mathrm{Z}_{\mathrm{j}}$ & $\mathrm{T}_{\mathrm{Z}}$ & $\mathrm{T}_{\mathrm{Zj}}$ \\
\hline 1 & 0.051 & $0.489 * * *$ & $0.711^{* * *}$ & $0.721 * * *$ & 0.115 & 0.299 & 0.219 & -0.228 & 0.273 & 0.071 \\
\hline 2 & 0.149 & $0.485 * * *$ & $0.523 * *$ & $0.549 * * *$ & 0.125 & 0.311 & 0.059 & 0.044 & 0.041 & -0.042 \\
\hline 3 & 0.049 & $0.558 * * *$ & $0.556 * * *$ & $0.519 * *$ & -0.107 & 0.117 & -0.142 & -0.041 & -0.141 & 0.098 \\
\hline 4 & 0.165 & $0.398 * *$ & $0.485 * *$ & $0.447 *$ & -0.172 & 0.144 & -0.291 & -0.178 & -0.264 & -0.054 \\
\hline 5 & 0.068 & $0.329 *$ & 0.312 & 0.301 & 0.042 & 0.016 & -0.168 & -0.187 & -0.149 & -0.286 \\
\hline 6 & 0.146 & $0.323 *$ & $0.353^{*}$ & 0.266 & -0.104 & 0.046 & -0.061 & 0.203 & -0.249 & -0.206 \\
\hline 7 & 0.067 & 0.121 & $0.489 * *$ & 0.321 & 0.029 & -0.035 & 0.109 & -0.103 & -0.124 & 0.059 \\
\hline 8 & -0.248 & 0.165 & 0.346 & 0.190 & -0.143 & -0.211 & 0.164 & -0.029 & 0.340 & -0.031 \\
\hline 9 & 0.236 & 0.037 & 0.048 & -0.120 & -0.316 & -0.275 & 0.080 & -0.003 & 0.071 & 0.178 \\
\hline 10 & -0.170 & 0.010 & 0.059 & -0.162 & -0.184 & $-0.462 * *$ & 0.008 & -0.096 & 0.026 & 0.242 \\
\hline
\end{tabular}

Spawning stock biomass

\begin{tabular}{|c|c|c|c|c|c|c|c|c|c|}
\hline Lag & Plaice & Sole & Saithe & Cod & Haddock & Whiting & N. pout & Sandeel & Herring \\
\hline 1 & $0.914 * * *$ & $0.764 * * *$ & $0.952 * * *$ & $0.971 * * *$ & $0.755^{* * *}$ & $0.763 * * *$ & $0.499 * * *$ & -0.128 & $0.946 * * *$ \\
\hline 2 & $0.791 * * *$ & $0.551 * * *$ & $0.857 * * *$ & $0.909 * * *$ & $0.437 * *$ & $0.494 * * *$ & 0.082 & -0.099 & $0.855 * * *$ \\
\hline 3 & $0.596 * * *$ & $0.443 * *$ & $0.741 * * *$ & $0.847 * * *$ & $0.356^{*}$ & $0.405 * *$ & 0.168 & -0.193 & $0.736 * * *$ \\
\hline 4 & $0.348 * *$ & $0.466 * * *$ & $0.614 * * *$ & $0.794 * * *$ & $0.423^{* *} *$ & $0.414 * *$ & 0.065 & -0.080 & $0.568 * * *$ \\
\hline 5 & 0.105 & $0.415^{* *}$ & $0.515^{* * *}$ & $0.743 * * *$ & $0.371 *$ & $0.366^{*}$ & -0.172 & 0.124 & $0.387 * * *$ \\
\hline 6 & -0.143 & $0.378 *$ & $0.431 * *$ & 0.696 *** & 0.200 & 0.217 & $-0.399 * *$ & -0.240 & 0.201 \\
\hline 7 & $-0.304 *$ & $0.316^{*}$ & $0.375 * *$ & $0.653 * * *$ & 0.092 & 0.109 & $-0.368 * *$ & 0.050 & -0.020 \\
\hline 8 & $-0.320 *$ & 0.290 & $0.356 * *$ & $0.621 * * *$ & -0.001 & 0.072 & -0.238 & 0.275 & -0.247 \\
\hline 9 & -0.296 & 0.172 & $0.356 * *$ & $0.592 * * *$ & -0.070 & 0.056 & $-0.375^{*}$ & 0.132 & $-0.423 * *$ \\
\hline 10 & -0.250 & 0.048 & 0.263 & $0.551 * * *$ & 0.112 & 0.151 & $-0.485 * *$ & -0.164 & $-0.601 * * *$ \\
\hline Lag & $\mathrm{T}\left({ }^{\circ} \mathrm{C}\right)$ & $\mathrm{Sp} \mathrm{T}\left({ }^{\circ} \mathrm{C}\right)$ & $\mathrm{Su} \mathrm{T}\left({ }^{\circ} \mathrm{C}\right)$ & $\mathrm{Au} \mathrm{T}\left({ }^{\circ} \mathrm{C}\right)$ & $\mathrm{Wi} \mathrm{T}\left({ }^{\circ} \mathrm{C}\right)$ & TD & Salinity & GSI & NAO \\
\hline 1 & $0.529 * * *$ & $0.358 *$ & $0.458^{* *}$ & 0.054 & $0.458 * *$ & $0.432 * *$ & $0.779 * * *$ & $0.632 * * *$ & $0.438^{*}$ \\
\hline 2 & $0.365^{*}$ & $0.574 * * *$ & 0.287 & -0.294 & $0.329 *$ & $0.417 *$ & $0.603 * * *$ & $0.416^{*}$ & 0.241 \\
\hline 3 & 0.129 & 0.191 & 0.206 & 0.030 & 0.121 & 0.052 & $0.466^{* *}$ & $0.345^{*}$ & 0.191 \\
\hline 4 & -0.055 & 0.322 & -0.046 & 0.077 & -0.105 & 0.060 & 0.266 & 0.256 & -0.068 \\
\hline 5 & 0.118 & 0.208 & 0.112 & 0.163 & -0.075 & 0.004 & 0.051 & 0.193 & 0.258 \\
\hline 6 & 0.232 & 0.285 & $0.453 * *$ & 0.046 & -0.131 & 0.217 & -0.037 & 0.201 & 0.263 \\
\hline 7 & 0.301 & $0.392 *$ & $0.504 * *$ & -0.185 & -0.120 & -0.033 & -0.185 & 0.271 & 0.047 \\
\hline 8 & 0.269 & $0.590 * * *$ & $0.429 *$ & -0.139 & -0.234 & -0.008 & -0.281 & 0.357 & 0.369 \\
\hline 9 & 0.250 & 0.324 & $0.407 *$ & -0.242 & -0.189 & -0.265 & $-0.297 *$ & $0.402 *$ & 0.350 \\
\hline 10 & -0.148 & $0.410 *$ & 0.027 & -0.192 & $-0.444 *$ & -0.231 & -0.274 & 0.353 & 0.116 \\
\hline
\end{tabular}

TABLE 2. - Correlations between numbers of fish larvae in CPR samples in the North Sea and spawning stock biomasses of fish stocks in the same year, one year previously (Lag 1) and two years previously (Lag 2). N = number of years of data to 1997 in each case except 1965 to 1984 for Mackerel; $\mathrm{r}=$ correlation coefficient; $\mathrm{r}(\mathrm{a})=$ correlation coefficient after removal of significant linear trends. Values in bold type are those remaining significant after application of Bonferroni correction.

\begin{tabular}{|c|c|c|c|c|c|c|c|c|c|c|}
\hline & Plaice & Sole & Saithe & Cod & Haddock & Whiting & $\mathrm{N}$ pout & Sandeels & Herring & Mackerel \\
\hline $\mathrm{n}$ & 41 & 41 & 31 & 35 & 35 & 38 & 24 & 22 & 38 & 20 \\
\hline $\mathrm{r}$ & -0.090 & $0.309 *$ & $-0.560 * * *$ & $-0.625 * * *$ & -0.316 & $-0.514 * * *$ & -0.257 & 0.232 & $0.519 * * *$ & $0.441 *$ \\
\hline $\begin{array}{l}\text { r(a) } \\
\text { Lag } 1\end{array}$ & 0.071 & $0.521 * * *$ & -0.258 & $-0.526 * * *$ & -0.049 & $-0.406 * *$ & -0.280 & 0.154 & $0.597 * * *$ & 0.107 \\
\hline $\mathrm{r}$ & -0.042 & 0.264 & $-0.562 * * *$ & $-0.625 * * *$ & -0.324 & $-0.624 * * *$ & -0.236 & 0.167 & $0.525 * * *$ & 0.078 \\
\hline $\begin{array}{l}\text { r(a) } \\
\text { Lag } 2\end{array}$ & 0.142 & $0.476^{* *}$ & -0.214 & $-0.402 *$ & 0.027 & $\mathbf{- 0 . 5 3 5 * * *}$ & -0.204 & 0.016 & $\mathbf{0 . 6 1 8} * * *$ & 0.224 \\
\hline $\mathrm{r}$ & -0.066 & 0.143 & $-0.554 * *$ & $-0.583 * * * *$ & $-0.347 *$ & $-0.706 * * * *$ & -0.229 & 0.119 & $0.515 * * *$ & -0.142 \\
\hline r(a) & 0.158 & $0.344 *$ & -0.206 & -0.260 & 0.024 & $\mathbf{- 0 . 6 2 1} * * *$ & -0.323 & 0.000 & $0.616 * * *$ & -0.179 \\
\hline
\end{tabular}

ment for multiple comparisons, and there is no relationship with cod recruitment two years previously.

The analysis of relationships between the interannual variations in cod recruitment and CPR young fish and physical environmental variables for the current year and one and two years previously are shown in Table 4. In each case the most significant relationships were with spring and annual mean 
a

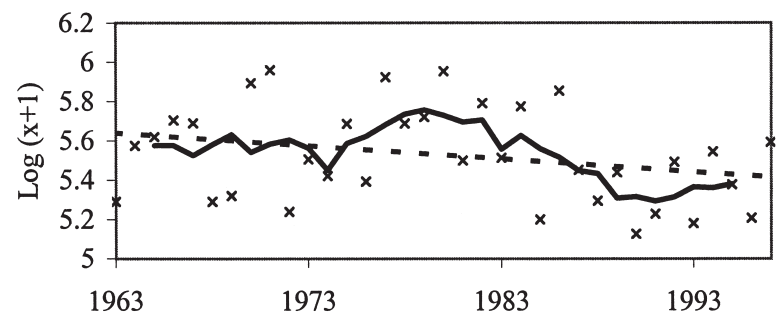

b CPR young fish
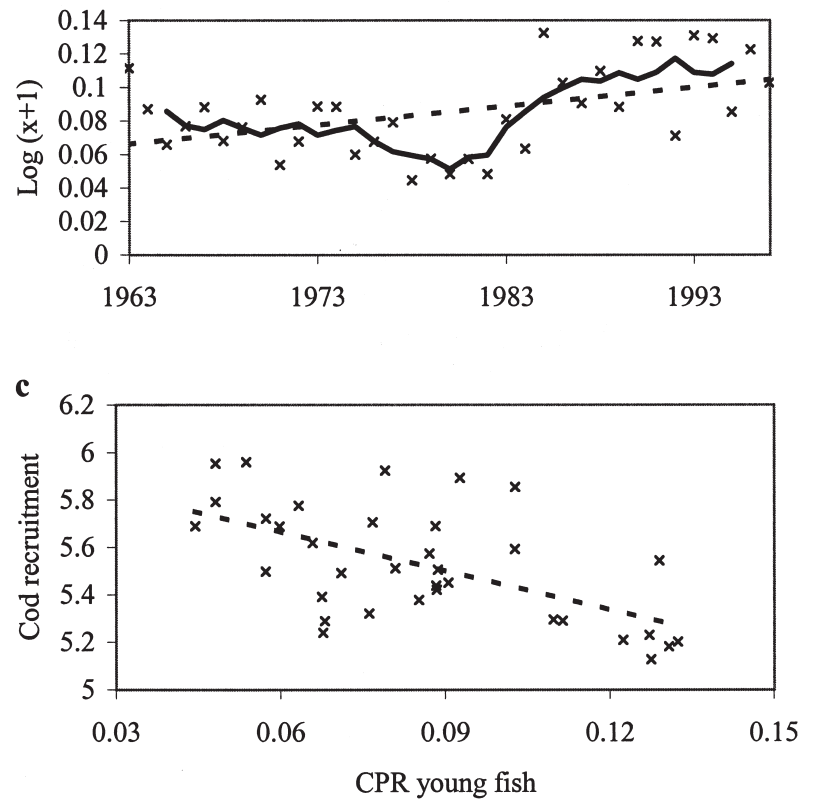

temperatures for the previous year, negative in the case of cod recruitment and positive in the case of CPR young fish.

The analysis in relation to colour and zooplankton biomass from the CPR survey is presented in Table 5. Cod recruitment was negatively correlated and CPR young fish were positively correlated with annual mean phytoplankton colour and the value for the period January to July for the previous year and, in the case of CPR young fish, for two years previously. Only the correlations with the previous year remained significant after removal of the linear trends. Correlations with timing of phytoplankton in the January to July period were generally weaker, but still significant. There was no linear trend in timing. It should be noted that the higher the value for timing, the later the peak, so the results indicate higher values for cod recruitment with later timing and higher numbers of fish in the CPR with earlier timing. There were correlations significant at the $1 \%$ level before removal of linear trends and at the 5\% level after removal of trends between CPR young fish and the annual mean and January to July mean zooplankton biomass values for the previous year.

FIG. 1. - (a) Cod recruitment (t) year 1, interannual variations. (b) CPR young fish, interannual variations, (c) Cod recruitment plotted against CPR young fish. Crosses mark the data points, the linear trend is given by the broken heavy line and the five-year running means are shown by the heavy continuous line.

TABLE 3. - Correlations between cod recruitment and CPR young fish in the current year and each variable and the other one and two years previously. Data from 1963 to 1997. The values in brackets are calculated after removal of the long-term trend for CPR young fish.

\begin{tabular}{|c|c|c|c|}
\hline & CPR fish (year y) & CPR fish (year y-1) & CPR fish (year y-2) \\
\hline $\begin{array}{l}\text { Cod Rec (year y) } \\
\text { Cod Rec (year y-1) } \\
\text { Cod Rec (year y-2) }\end{array}$ & $\begin{array}{l}\mathbf{- 0 . 5 8 9} * * *(-\mathbf{0 . 5 4 1} * * *) \\
\mathbf{- 0 . 4 8 3} * *(-0.399 *) \\
-0.260(-0.143)\end{array}$ & $0.087(0.076)$ & $-0.589 * * *(-0.516 * * *)$ \\
\hline
\end{tabular}

TABLE 4. - Correlations between cod recruitment (Cod rec) and CPR young fish (CPR fish) in the North Sea and annual mean salinity, annu$\mathrm{al}$ and seasonal mean temperatures and the temperature difference for the current year and one and two years previously. Data from 1963 to 1997. The rows with labels ending with "a" are results after removal of significant linear trends, nt= no significant linear trends. For further explanation see captions to Tables 1 and 2 .

\begin{tabular}{|c|c|c|c|c|c|c|c|}
\hline & Salinity & $\operatorname{Sp~T~}\left({ }^{\circ} \mathrm{C}\right)$ & $\mathrm{Su} \mathrm{T}\left({ }^{\circ} \mathrm{C}\right)$ & $\mathrm{Au} \mathrm{T}\left({ }^{\circ} \mathrm{C}\right)$ & Wi T $\left({ }^{\circ} \mathrm{C}\right)$ & $\mathrm{T}\left({ }^{\circ} \mathrm{C}\right)$ & TD \\
\hline Cod rec (year y) & -0.103 & $-0.353 *$ & $-0.339 *$ & 0.138 & -0.264 & $-0.324 *$ & 0.174 \\
\hline Cod rec (year y)a & $\mathrm{nt}$ & -0.223 & 0.053 & nt & -0.057 & -0.125 & nt \\
\hline Year $(y+1)$ & -0.030 & $-0.525 * *$ & -0.263 & $-0.489 * *$ & $-0.474 * *$ & $\mathbf{- 0 . 5 8 3} * * *$ & 0.040 \\
\hline Year $(y+1) a$ & nt & $-0.398 *$ & $-0.397 *$ & nt & -0.330 & $-0.450 * *$ & nt \\
\hline Year $(y+2)$ & 0.029 & -0.131 & -0.235 & 0.039 & -0.111 & -0.175 & -0.242 \\
\hline Year $(y+2) a$ & $\mathrm{nt}$ & 0.031 & $-0.355^{*}$ & $\mathrm{nt}$ & 0.046 & 0.022 & $\mathrm{nt}$ \\
\hline CPR fish & 0.042 & 0.192 & 0.165 & -0.158 & 0.067 & 0.119 & 0.326 \\
\hline CPR fish a & 0.123 & 0.200 & -0.098 & -0.266 & -0.165 & -0.159 & 0.263 \\
\hline Year $(y+1)$ & -0.076 & $0.527 * *$ & 0.313 & 0.304 & 0.390 * & $\mathbf{0 . 5 2 4} * *$ & 0.303 \\
\hline Year $(y+1) a$ & -0.007 & $0.378^{*}$ & 0.334 & 0.242 & 0.196 & 0.322 & 0.249 \\
\hline Year $(y+2)$ & -0.164 & $0.416^{*}$ & 0.339 & 0.149 & 0.302 & $0.372 *$ & 0.310 \\
\hline Year $(y+2) a$ & -0.111 & 0.031 & 0.093 & 0.091 & 0.046 & 0.161 & 0.244 \\
\hline
\end{tabular}


TABLE 5. - Cod recruitment and CPR young fish. Correlations with annual means and values for January to July of phytoplankton colour, the timing of its occurrence in the plankton, zooplankton biomass and its timing. Annual means and means for January to June only used. Data from 1963 to 1997 . For further explanation see captions to Tables 1 and 2 .

\begin{tabular}{|c|c|c|c|c|}
\hline & Cod Rec & $\mathrm{r}(\mathrm{a})$ & CPR fish & $\mathrm{r}(\mathrm{a})$ \\
\hline P (Year y) & $-0.422 * *$ & -0.317 & $0.460 * *$ & 0.216 \\
\hline Year y-1 & $-0.486 * *$ & $-0.360 *$ & $0.592 * * *$ & $0.425 *$ \\
\hline Year y-2 & $-0.390 *$ & -0.232 & $\mathbf{0 . 5 0 8} * *$ & 0.327 \\
\hline$P_{j}($ Year $y)$ & $-0.399 *$ & -0.287 & $0.435 * *$ & 0.250 \\
\hline Year y-1 & $\mathbf{- 0 . 5 8 2} * * *$ & $-0.481 * *$ & $0.648 * * *$ & $0.516 * *$ \\
\hline Year y-2 & $-0.329 *$ & -0.265 & $0.480 * *$ & 0.281 \\
\hline $\mathrm{T}_{\mathrm{p}}($ Year $\mathrm{y})$ & 0.067 & nt & -0.107 & -0.019 \\
\hline Year y-1 & 0.226 & nt & -0.247 & -0.213 \\
\hline Year y-2 & -0.003 & nt & -0.003 & 0.040 \\
\hline $\mathrm{T}_{\mathrm{pi}}($ Year $\mathrm{y})$ & $0.404 *$ & nt & $-0.408 *$ & $-0.405^{*}$ \\
\hline Year y-1 & 0.250 & nt & $-0.426 * *$ & $-0.462 * *$ \\
\hline Year y-2 & $0.416^{*}$ & nt & $-0.453 * *$ & $-0.486 * *$ \\
\hline Z (Year y) & -0.143 & $\mathrm{nt}$ & 0.300 & 0.318 \\
\hline Year y-1 & -0.116 & $\mathrm{nt}$ & 0.314 & $0.396^{*}$ \\
\hline Year y-2 & -0.164 & $\mathrm{nt}$ & 0.281 & 0.243 \\
\hline $\mathrm{Z}_{\mathrm{j}}$ (Year y) & -0.250 & $\mathrm{nt}$ & 0.223 & 0.165 \\
\hline Year y-1 & -0.116 & nt & $0.431 * *$ & $0.408 *$ \\
\hline Year y-2 & -0.021 & $\mathrm{nt}$ & 0.208 & 0.113 \\
\hline $\mathrm{T}_{\mathrm{Z}}($ Year y) & 0.136 & $\mathrm{nt}$ & -0.047 & 0.005 \\
\hline Year $y-1$ & 0.036 & $\mathrm{nt}$ & -0.032 & 0.067 \\
\hline Year y-2 & 0.007 & nt & 0.047 & 0.149 \\
\hline $\mathrm{T}_{\mathrm{Zj}}$ & 0.136 & nt & 0.025 & 0.149 \\
\hline Year y-1 & 0.036 & nt & 0.043 & 0.108 \\
\hline Year y-2 & 0.007 & $\mathrm{nt}$ & -0.056 & -0.014 \\
\hline
\end{tabular}

These were not significant after adjustment for multiple correlations.

Relationships with the NAO and the GSI are given in Table 6. Cod recruitment was most strongly correlated with the NAO for the previous year, the correlation remaining significant after correction for multiple comparisons and the removal of the linear trend. CPR young fish were most strongly correlated with the GSI two years previously before removal of the long-term trend but after removal of the trend only the correlation between CPR young fish and the GSI in the same year remained significant.

Correlations between cod recruitment and fish spawning stock from two years previously to two years later are listed in Table 7. Although over the whole period from 1963 cod recruitment does not show a significant linear trend, during the periods from 1974 and 1976 for which data are available for Norway pout and sandeels there is such a trend and adjustments for this are incorporated into the analysis. Correlations with other gadoids were mainly positive, while those with herring were negative. The correlations with sandeels were very variable.

TABLE 6. - Cod recruitment and CPR young fish. Correlations with the Gulf Stream Index and North Atlantic Oscillation Index for the current year and for one and two years previously. Data for GSI from 1966 to 1997, for NAO from 1963 to 1997. For further explanation see captions to Tables 1 and 2 .

\begin{tabular}{|c|c|c|c|c|c|c|}
\hline & GSI (year y) & $\mathrm{r}(\mathrm{a})$ & GSI (year y-1) & $\mathrm{r}(\mathrm{a})$ & GSI (year y-2) & $\mathrm{r}(\mathrm{a})$ \\
\hline $\begin{array}{l}\text { Cod rec } \\
\text { CPR fish }\end{array}$ & $\begin{array}{l}-0.403^{*} \\
\mathbf{0 . 5 4 6}\end{array}$ & $\begin{array}{c}-0.249 \\
0.343 *\end{array}$ & $\begin{array}{l}-0.356 * \\
\mathbf{0 . 5 4 7 * * *}\end{array}$ & $\begin{array}{r}-0.223 \\
0.332\end{array}$ & $\begin{array}{l}-0.218 \\
\mathbf{0 . 5 5 1} * * *\end{array}$ & $\begin{array}{r}-0.076 \\
0.316\end{array}$ \\
\hline & NAO (year y) & & NAO (year y-1) & & NAO (year y-2) & \\
\hline $\begin{array}{l}\text { Cod rec } \\
\text { CPR fish }\end{array}$ & $\begin{array}{r}-0.128 \\
0.090\end{array}$ & $\begin{array}{r}0.026 \\
-0.199\end{array}$ & $\begin{array}{c}-\mathbf{0 . 5 2 1} * * * * \\
0.376^{*}\end{array}$ & $\begin{array}{c}\mathbf{- 0 . 4 1 2} * \\
0.122\end{array}$ & $\begin{array}{l}-0.318 \\
\mathbf{0 . 4 7 5} * *\end{array}$ & $\begin{array}{r}-0.185 \\
0.176\end{array}$ \\
\hline
\end{tabular}

TABLE 7. - Correlations between cod recruitment for the current year and fish spawning stock biomass in the North Sea for the same year and for one and two years previously (lag 1 and lag 2). For further explanation see captions to Tables 1 and 2.

\begin{tabular}{|c|c|c|c|c|c|c|c|c|c|c|}
\hline & Plaice & Sole & Saithe & Cod & Haddock & Whiting & $\mathrm{N}$ pout & Sandeels & Herring & Mackerel \\
\hline \multicolumn{11}{|l|}{ Year y-2 } \\
\hline $\mathrm{r}$ & -0.037 & -0.144 & $0.388 *$ & $0.370 *$ & 0.207 & $0.551 * * *$ & $0.446^{*}$ & -0.232 & $-0.425^{*}$ & -0.099 \\
\hline $\mathrm{r}(\mathrm{a})$ & -0.240 & -0.296 & 0.187 & 0.167 & -0.297 & $0.472 *$ & 0.067 & -0.241 & nt & 0.157 \\
\hline \multicolumn{11}{|l|}{ Year y-1 } \\
\hline $\mathrm{r}$ & -0.063 & -0.223 & $0.349 *$ & $0.399 *$ & $0.440 *$ & $0.585 * * *$ & 0.341 & 0.093 & $-0.360 *$ & -0.046 \\
\hline r(a) & -0.264 & -0.379 & 0.195 & 0.224 & 0.303 & 0.539** & 0.237 & $0.678 * * *$ & $\mathrm{nt}$ & -0.0102 \\
\hline \multicolumn{11}{|l|}{ Year y } \\
\hline $\mathrm{r}$ & 0.009 & -0.277 & 0.309 & $0.428 *$ & 0.326 & 0.220 & 0.142 & $-0.423 *$ & $-0.353 *$ & -0.339 \\
\hline $\mathrm{r}(\mathrm{a})$ & -0.160 & $-0.434^{*}$ & 0.123 & $0.429 *$ & 0.121 & 0.109 & 0.087 & -0.398 & nt & -0.306 \\
\hline \multicolumn{11}{|l|}{ Year $y+1$} \\
\hline $\mathrm{r}$ & 0.186 & -0.193 & 0.299 & $0.420 *$ & 0.088 & 0.184 & 0.248 & $0.444 *$ & -0.314 & 0.176 \\
\hline $\mathrm{r}(\mathrm{a})$ & 0.057 & $-0.351 *$ & 0.179 & $0.395 *$ & 0.329 & $0.520 * *$ & 0.361 & 0.301 & $\mathrm{nt}$ & -0.166 \\
\hline \multicolumn{11}{|l|}{ Year $y+2$} \\
\hline $\mathrm{r}$ & 0.137 & -0.202 & 0.248 & $0.348 *$ & 0.133 & 0.283 & 0.122 & -0.273 & -0.206 & 0.268 \\
\hline $\mathrm{r}(\mathrm{a})$ & 0.027 & -0.330 & -0.150 & $0.343 *$ & 0.023 & $0.501 * *$ & -0.163 & -0.125 & nt & 0.181 \\
\hline
\end{tabular}


TABLE 8. - Results of multiple regression analysis. (a) Relating cod recruitment $(\log x+1)$ to combinations of 5 variables, best results using 2, 3, 4 and all 5 variables. (b) coefficients and constant of the regression equations from (a). (c) Relating CPR fish to combinations of 6 variables, best results using 2, 3, 4, 5 and all 6 variables. (d) coefficients and constant of regression equations from (c). For futher explanation see Tables 1 and 2. Data for variables for one or two years previously are indicated by $(y-1)$ and $(y-2)$.

\begin{tabular}{lll}
\hline (a) & & \\
$\mathrm{n}$ & Variables & $\mathrm{r}$ \\
\hline 2 & $\mathrm{NAO}(\mathrm{y}-1), \mathrm{CPR}$ fish & $0.657 * * *$ \\
3 & $\mathrm{~T}\left({ }^{\circ} \mathrm{C}\right)(\mathrm{y}-1), \mathrm{P}_{\mathrm{j}}(\mathrm{y}-1), \mathrm{CPR}$ fish & $0.670 * * *$ \\
4 & $\mathrm{~T}\left({ }^{\circ} \mathrm{C}\right)(\mathrm{y}-1), \mathrm{P}_{\mathrm{j}}(\mathrm{y}-1), \mathrm{NAO}(\mathrm{y}-1), \mathrm{CPR}$ fish & $0.683 * * *$ \\
$\mathrm{All}$ & $\mathrm{T}\left({ }^{\circ} \mathrm{C}\right)(\mathrm{y}-1), \mathrm{P}_{\mathrm{j}}(\mathrm{y}-1), \mathrm{T}_{\mathrm{pj}}(\mathrm{y}-1), \mathrm{NAO}(\mathrm{y}-1), \mathrm{CPR}$ fish & $0.683^{* * *}$ \\
& & \\
$(\mathrm{c})$ & \\
$\mathrm{n}$ & $\mathrm{Variables}$ & $\mathrm{r}$ \\
\hline 2 & $\mathrm{P}_{\mathrm{j}}(\mathrm{y}-1), \mathrm{GSI}(\mathrm{y}-1)$ & $0.744 * * *$ \\
3 & $\mathrm{P}_{\mathrm{j}}(\mathrm{y}-1), \mathrm{T}_{\mathrm{pj}}(\mathrm{y}-1), \mathrm{GSI}(\mathrm{y}-1)$, & $0.759 * * *$ \\
4 & $\mathrm{P}_{\mathrm{j}}(\mathrm{y}-1), \mathrm{T}_{\mathrm{pj}}(\mathrm{y}-1), \mathrm{GSI}(\mathrm{y}-1), \mathrm{Cod} \mathrm{rec}$ & $0.772 * * *$ \\
5 & $\mathrm{P}_{\mathrm{j}}(\mathrm{y}-1), \mathrm{T}_{\mathrm{pj}}(\mathrm{y}-1), \mathrm{NAO}(\mathrm{y}-2), \mathrm{GSI}(\mathrm{y}-1), \mathrm{Cod} \mathrm{rec}$ & $0.776^{*} * *$ \\
6 & $\mathrm{~T}\left({ }^{\circ} \mathrm{C}\right)(\mathrm{y}-1), \mathrm{P}_{\mathrm{j}}(\mathrm{y}-1), \mathrm{T}_{\mathrm{pj}}(\mathrm{y}-1), \mathrm{NAO}(\mathrm{y}-2), \mathrm{GSI}(\mathrm{y}-1), \mathrm{Cod} \mathrm{rec}$ & $0.778^{* * *}$ \\
\hline
\end{tabular}

\begin{tabular}{lccccc}
\hline (b) & & & & & \\
$\mathrm{T}\left({ }^{\circ} \mathrm{C}\right)$ & $\mathrm{P}_{\mathrm{j}}$ & $\mathrm{T}_{\mathrm{pj}}$ & NAO & CPR fish & $\mathrm{b}$ \\
\hline & & & -0.030 & -4.532 & 5.922 \\
-0.112 & -0.114 & & & -3.216 & 7.017 \\
-0.078 & 0.019 & & -0.019 & -4.080 & 6.551 \\
-0.016 & -0.138 & -0.025 & -0.022 & -3.282 & 6.245
\end{tabular}

\begin{tabular}{rcccccc}
$(\mathrm{d})$ & & & & & \\
$\mathrm{T}\left({ }^{\circ} \mathrm{C}\right)$ & $\mathrm{P}_{\mathrm{j}}$ & $\mathrm{T}_{\mathrm{pj}}$ & $\mathrm{NAO}$ & $\mathrm{GSI}$ & Cod rec & $\mathrm{b}$ \\
\hline 0.033 & & & 0.009 & & 0.047 \\
0.028 & -0.017 & & 0.009 & & 0.133 \\
0.022 & -0.017 & & 0.008 & -0.019 & 0.248 \\
& 0.021 & -0.017 & 0.001 & 0.007 & -0.019 & 0.250 \\
-0.004 & 0.023 & -0.017 & 0.001 & 0.007 & -0.021 & 0.296 \\
\hline
\end{tabular}

Multiple regressions were calculated between the cod recruitment data for each combination of temperature, $\mathrm{P}_{\mathrm{j}}, \mathrm{T}_{\mathrm{pj}}$ and the NAO for the previous year and $\mathrm{CPR}$ fish for the same year. The correlation between the original data and the results of applying these equations varied between 0.527 and 0.683 . The best combinations of 2, 3 and 4 variables and the results for all 5 are given in Table 8a and the coefficients fitted to the variables are listed in Table 8b. The best fit using two variables was that with the NAO and CPR young fish. Inclusion of the timing of the spring bloom in the previous year does not improve the result significantly. Replacing CPR young fish with herring spawning stock biomass for the previous year resulted in worse fits for the combinations of $2(\mathrm{r}=$ $0.616), 3(\mathrm{r}=0.655)$ and $4(\mathrm{r}=0,680)$ variables and no improvement with all 5 variables $(r=0.683)$.

Comparable analyses were carried out relating CPR young fish to the NAO for two years previously, temperature, $\mathrm{P}_{\mathrm{j}}, \mathrm{T}_{\mathrm{pj}}$ and the GSI for the previous year and cod recruitment for the same year. The $r-$ values were all $>0.492$ and the results for the best combinations of 2, 3, 4, 5 and all 6 variables are listed in Table 8c and $8 \mathrm{~d} . \mathrm{P}_{\mathrm{j}}$ and the GSI was the best pair of variables. Including the NAO for two years previously and temperature for the previous year provided little improvement to the fit provided by the best 4 variables.

\section{DISCUSSION}

The positive correlation between CPR young fish and the biomass of herring and the positive but not significant relationship with sandeels are consistent with clupeids and ammodytids being the dominant components of the CPR young fish counts and these counts being dependant on the spawning stocks. The negative correlations between CPR young fish and most gadoid spawning stocks are consistent with density dependent predation by gadoids, and comparable with the effects of variability in hake (Merluccius productus) on herring off the west coast of Canada (Ware and McFarlane, 1995). The results of the multiple regression analyses (Table 8), with the CPR young fish being one of the variables which provided the best fit to the cod recruitment data, provide added support to the indications that a trophic relationship is involved. Adult cod eat fish including herring, gadoids and sand eels (e.g. Brown and Cheng, 1946; Grosslein et al., 1980) although fish comprise a smaller proportion of cod stomach contents in the North Sea than in some other areas (Pálsson, 1994). Neither Sysoeva and Degtereva (1965) nor Bainbridge and McKay (1968) recorded fish larvae as a significant component of cod larval diet. The depletion of the North Sea spawning stock of mackerel in recent years may be linked with the recovery in herring and the numbers of fish in the CPR. However the catch in the North Sea of migrants from other mackerel spawning stocks remains high (Anon., 1999). Clupeidae and Ammodytidae are planktivores (e.g. Hardy, 1924) and would compete for resources with the cod larvae and juveniles. Smaller fish and early stages of others figure in their diets, so these would have some predatory impact on each other and even within species.

The negative correlations between cod recruitment and CPR young fish in the same year and the previous year, the year in which the recruits were 


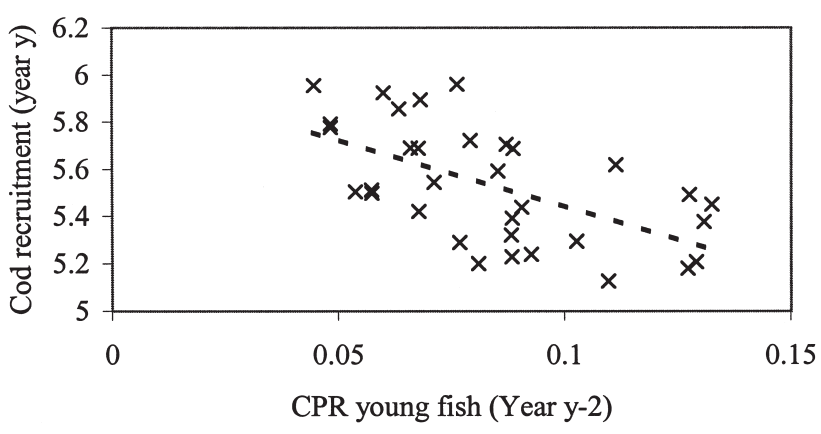

FIG. 2. - Cod recruitment plotted against CPR young fish for two years previously. For further explanation see Fig. 1.

spawned (Table 3), is suggestive of an influence of predation by cod. In the plot of cod recruitment against CPR young fish numbers (Fig. 1c) only one cod recruitment value is above the regression line among the eight highest CPR young fish values, those for 1963, and seven of the years from 1985 to 1996. Only two cod recruitment values fall below the regression line among the eight lowest values, those for 1971 and seven of the years between 1975 and 1984. This suggests that the effects of any trophic relationship only become evident in the data at the highest and lowest levels. There is no such pattern in Figure 2, the plot of cod recruitment against numbers of CPR young fish two years earlier. The negative correlation with CPR young fish two years previously may not be a result of trophic relationships but it may be significant that the lag is the same as the two-year lag between NAO and GSI (Taylor and Stephens, 1998). The NAO is of greater importance than the GSI to cod recruitment and the reverse is true for CPR young fish.

The significant reciprocal relationships of cod recruitment and CPR young fish with temperature in the previous year are consistent with the findings of Svendsen et al. (1995). They found that the success of spawning and larval development was related to low temperature in the first quarter of the year for cod, high temperature in May for Ammodytidae and strong or persistent southerly winds around March for herring (Svendsen et al., 1995). In view of the correlation of CPR young fish data with herring spawning stock (Table 2), the persistence of some correlation with temperature two years previously can be attributed to survival and breeding of the fish from successful year classes into subsequent years.

The importance of success of spawning and larval development in the previous year is also reflected in the relationship of CPR young fish with phy- toplankton colour and the timing of the spring bloom in the CPR survey (Table 5). The results showing that cod recruitment is inversely related to phytoplankton colour and the lack of any demonstrable relationship with zooplankton biomass is perhaps surprising. However, Svendsen et al. (1995) concluded that cod recruitment in the North Sea was most successful with a combination of low temperature and low Atlantic inflow. Productivity in the North Sea is generally enhanced following high inflow from the Atlantic (e.g. Reid et al., 1993). Zooplankton biomass in January to July of the preceding year was more significantly correlated with the CPR young fish than was the annual mean. This suggests that the food available to the larvae in the spring may be a contributory factor, but after correcting for multiple comparisons the correlations are not significant so the evidence is inconclusive.

The negative correlation between cod recruitment and the NAO in the previous year, the most significant of those with climatic indices, and the results of the analyses of multiple regressions again supports the significance of larval survival the previous year. The positive relationship between CPR young fish and the GSI over a three-year period can be interpreted as dependence of stocks with generation times of $>1$ year on climatic influences over a comparable time scale. The fact that after removal of the linear trends only the correlation with the GSI in the current year remained significant supports this interpretation.

At times when the NAO is high, westerly winds are strong and inflow of oceanic water into the North Sea is high. Sea surface temperature and CPR phytoplankton colour in the North Sea have been positively correlated with the NAO over the period studied here. The combination of high temperature and high oceanic inflow is disadvantageous for cod spawning and larval development, so recruitment of one-year-old fish in the following year is low (negative correlations in Tables 4, 5 and 6). These conditions are to the advantage of the fish that contribute substantially to the CPR young fish counts. Conversely, at times of low NAO the situation favours cod spawning. The Gulf Stream Index, with its two year lag behind the NAO (Table 6), exerts its influence through the weather in spring, which extends through the plankton community for the year, (A.H. Taylor, unpublished). A two year lag between CPR young fish and cod recruitment (Table 3) and between other variables and CPR young fish is evident in Table 5, where there is a strong positive rela- 
tionship with the timing of the spring bloom of phytoplankton two years previously. The fact that the negative correlations between cod recruitment and CPR young fish are stronger than those with any of the environmental variables measured here may be the result of trophic relationships working in the same direction as the physical forcing. The trophic relationships may comprise increased numbers of cod preying on a depleted stock of clupeids and sandeels following low NAOs, or lower numbers of cod feeding on larger clupeid and stocks after high NAOs. Alternatively, when conditions are favourable to clupeids and sandeels, competition with and preying on the planktonic stages of cod would be higher than otherwise. The relative importance of the CPR young fish to cod recruitment in the multiple regressions would support the impact on cod recruitment of competition with and predation on the planktonic stages from the stocks of clupeidae and sandeels.

The form of the five-year running means in Figure $1 \mathrm{a}$ and $1 \mathrm{~b}$ are suggestive of cyclical processes. The two plots are in phase but of opposite form. The time series of other variables analysed here include cyclical patterns and the possibility that similar but independent cyclical patterns, in phase or slightly out of phase, could give rise to artifactual correlations cannot be totally discarded. However, it should be noted that the change in NAO index values between the periods 1963-67 (mean NAO index -2.67) and 1992-1997 (mean NAO index 1.81) is greater than the cyclical fluctuations in the intervening period. Similarly, the overall trends in temperature and the GSI during this period are greater than the cycles within it. Given the increasing weight of evidence that ecological changes are related to the NAO and correlated variables (Reid et al., 1998), it would seem that the cycles are part of the "signal" of real relationships rather than artifactual "noise", particularly where correlations between residual variations remain after removal of linear trends.

Prediction of cod recruitment and the numbers of fish caught in the CPR survey in the North Sea should therefore start with prediction of the NAO. Taylor and Stephens (1998) have shown that the NAO together with other atmospheric inputs, such as the ENSO, can provide the basis for a prediction of the GSI. The relationship between CPR young fish and the GSI indicates that if that can be predicted then progress can be made towards predicting the numbers of young fish taken in the CPR. Together with the NAO this provides a basis for predicting cod recruitment and hence a contribution to prediction of future stock size. Other factors that would need to be taken into account are the longevity of fish, which provides a substantial degree of persistence from year to year in the numbers in the North Sea, and the effects of exploitation which may dominate after depletion of the stock (Hutchings, 2000).

\section{ACKNOWLEDGEMENTS}

The work was financed from Phase 1 of the Marine Productivity programme of the UK Natural Environment Research Council. The CPR survey depends on the voluntary cooperation of owners, masters and crews of merchant ships that tow the recorders.

\section{REFERENCES}

Anon. 1999. - Report of the ICES Advisory Committee on Fishery Management. ICES Coop. Res. Rep., 236: (1)1-416 \& (2) 1405 .

Bainbridge, V. and G.A. Cooper. - 1971. Populations of Sebastes larvae in the North Atlantic. Res. Bull. Int. Commn NW Atlantic. Fish., 8: 27-35.

Bainbridge, V. and B.J. McKay. - 1968. The feeding of cod and redfish larvae. Spec. Publ. Int. Commn NW Atlantic. Fish., 7: 187-217.

Bainbridge, V., G.A. Cooper and P.J.B. Hart. - 1974. Seasonal fluctuations in the abundance of the larvae of mackerel and herring in the northeastern Atlantic and North Sea. In: J.H.S. Blaxter (ed.), The early life history of fish, pp. 159-169. Springer-Verlag, Berlin.

Brander, K. - 1992. A re-examination of the relationship between cod recruitment and Calanus finmarchicus in the North Sea. ICES Mar. Sci. Symp., 195: 393-401.

Brander, K. - 1994. The location and timing of cod spawning around the British Isles. ICES J. mar. Sci., 51: 71-89.

Brander, K. and P.C.F. Hurley. - 1991. Distribution of the early stage Atlantic cod (Gadus morhua), haddock (Melanogrammus aeglefinnus), and witch flounder (Glyptocephalus cynoglossus) eggs on the Scotian shelf: a reappraisal of evidence on the coupling of cod spawning and plankton production. Can. J. Fish Aquat. Sci., 49: 238-251.

Brown, W.W. and C. Cheng. - 1946. Investigations into the food of cod (Gadus callarias L.) off Bear Island, and of the cod and haddock ( $G$. Aegelfinus L.) off Iceland and the Murman coast. Hull. Bull. mar. Ecol., 18: 35-71.

Colebrook, J.M. - 1960. Continuous plankton records: methods of analysis, 1950-59. Bull. mar. Ecol., 5: 51-64.

Colebrook, J.M. and G.A. Robinson. - 1965. Continuous plankton records: seasonal cycles of phytoplankton and copepods in the north-eastern Atlantic and the North Sea. Bull. mar. Ecol., 6: 123-139.

Coombs, S.H. - 1980. Continuous plankton records: a plankton atlas of the north Atlantic and the North Sea. Supplement 5 young fish, 1948-1972. Bull. mar. Ecol., 8: 229-281.

Craig, R.E. - 1960. A note on the dependence of catches on temperature and wind in the Buchan pre-spawning herring fishery. J. Cons. Int. Explor. Mer, 25: 185-208.

Cushing, D.H. - 1969. The regularity of the spawning season of some fishes. J. Cons. Int. Explor. Mer., 33: 81-92.

Grosslein, M.D., R.W. Langton and M.P. Sissenwine. - 1980. Recent fluctuations in pelagic fish stocks of the northwest Atlantic, Georges Bank region, in relation to species interactions. Rapp. P.-v. Réun. Cons. Int. Explor. Mer, 177: 374-404. 
Hardy, A.C. - 1924. The herring in relation to its animate environment. Part I. The food and feeding habits of the herring with special reference to the east coast of England. Fish. Invest. Ser. II., 7: 1-53.

Hart, P.J.B. - 1974. The distribution and long-term changes in abundance of larval Ammodytes marinus (Raitt) in the North Sea. In: J.H.S. Blaxter (Ed.), The early life history of fish, pp. 171-182. Springer-Verlag, Berlin.

Hays, G.C. and J.A. Lindley. - 1994. Estimating chlorophyll $a$ abundance from the "phytoplankton colour" recorded by the Continuous Plankton Recorder survey: validation with simultaneous fluorometry. J. Plankton Res. 16: 23-34.

Hays, G.C. and A.J. Warner. - 1993. Consistency of towing speed and sampling depth for the Continuous Plankton Recorder. $J$. mar. Biol. Ass. U.K., 73: 967-970

Horwood, J., D. Cushing and T. Wyatt. - 2000. Planktonic determination of variability and sustainability of fisheries. J. Plankton Res. 16: 23-34.

Hurrell, J.W. - 1995. Decadal trends in the North Atlantic Oscillation: regional temperatures and precipitation. Science, 269: 676-679.

Hutchings, J.A. - 2000. Collapse and recovery of marine fishes. Nature, 406: 882-885.

Miller, R.G. - 1981. Simultaneous statistical inference. $2^{\text {nd }}$ ed. Springer Verlag.

O’ Brien, C.M., C.J. Fox, B. Planque, and J. Case. - 2000. Climate variability and North Sea Cod. Nature, 440: 142.

Pálsson, Ó.K. - 1994. A review of the trophic interactions of cod stocks in the North Atlantic. ICES mar. Sci. Symp., 198: 553575 .

Rae, K.M. - 1952. Continuous plankton records: explanation and methods, 1946-1949. Hull Bull. mar. Ecol., 3 : 135-155.

Reid, P.C., E.J.V. Battle, S.D. Batten and K.M. Brander. - 2000. Impacts of fisheries on plankton community structure. ICES J. mar. Sci., 57: 495-502

Reid, P.C., B. Planque and M.E.Edwards. - 1998. Is observed variability in the long-term results of the Continuous Plankton
Recorder survey a response to climate change. Fish. Oceanogr., 7: 282-288

Reid, P.C., S.C. Surey-Gent, H.G. Hunt \& A.E. Durrant. - 1993. Thalassiothrix longissima, a possible oceanic indicator species in the North Sea. ICES Mar. Sci. Sym., 195: 268-277.

Robinson, G.A., 1970. - Continuous plankton records: variation in the seasonal cycle of phytoplankton in the north Atlantic. Bull. mar. Ecol., 6: 333-345.

Robinson, G.A. and A.R. Hiby. - 1978. The Continuous Plankton Recorder Survey. In:- A. Sournia (Ed.) Phytoplankton Manual pp 59-63, UNESCO.

Rodionov, S.N. - 1995. Atmospheric teleconnections and coherent fluctuations in recruitment to North Atlantic cod (Gadus morhua) stocks. Can. Spec. Publ.. Fish Aquat. Sci., 121: 45-55.

Rothschild, B.J. - 1998. Year class strengths of zooplankton in the North Sea and their relation to cod and herring abundance. $J$. Plankton Res., 20: 1721-1741.

Svendsen, E., A. Algel, S.A. Iversen, D.W. Skagen and O Semstad. - 1995. Influence of climate on recruitment and migration of fish stocks in the North Sea. Can. Spec. Publ.. Fish Aquat. Sci. 121: 641-653.

Sysoeva, T.K. and A.A. Degtereva. - 1965. The relationship between the feeding of cod larvae and pelagic fry and their principal food organisms. Int. Comm. Northwest Atl. Fish. Spec. Publ., 6: 411-416.

Taylor, A.H. - 1995. North-South shifts of the Gulf Stream and their climatic connection with the abundance of zooplankton in the UK and its surrounding seas. ICES J. mar. Sci., 52: 711721.

Taylor, A.H. and J.A. Stephens. - 1998. The North Atlantic Oscillation and the latitude of the Gulf Stream. Tellus, 50A: 134-142.

Ware, D.M. and G.A. McFarlane. - 1995. Climate induced changes in pacific hake (Merluccius productus) abundance and pelagic community interactions in the Vancouver Island upwelling system. Can. Spec. Publ. Fish Aquat. Sci., 121: 509-521.

Warner, A.J. and G.C. Hays. - 1994. Sampling by the Continuous Plankton Recorder survey. Prog. Oceanogr., 34: 237-256. 